\title{
The Timing Experiments of Libet and Grey Walter ${ }^{1}$
}

\author{
John M Ostrowick \\ School of Computer Science, University of the Witwatersrand \\ Wits 2050, Johannesburg \\ South Africa \\ E-mail: jon@cs.wits.ac.za
}

\begin{abstract}
The neurological experiments conducted by Benjamin Libet (1985) and Grey Walter (1993, in Dennett) provide evidence that our actions are caused by non-conscious brain events beyond our conscious awareness. Normally, we assume that our conscious choices lead us to do things. If these researchers have interpreted their evidence correctly, it may be that we lack free-will, for we could not control a non-conscious brain state. Libet however provides evidence that agents can "change their minds" just before performing some action. He felt that this was the elbow-room for free-will. But it may be inconsistent for him to suggest this, since his evidence indicates that there is no room for conscious choice. In this paper we discuss these results and various objections to the interpretation of the work.
\end{abstract}

\section{Section 1 - Introduction}

Most persons, when asked about their choices and will, would refer to mental or conscious states as subjectively experienced, and would make no reference to underlying brain processes. Yet many people today also accept the scientific view that our mental processes, such as the processes of choice, are phenomena inextricably related to or caused by our underlying brain processes.

Benjamin Libet and W. Grey Walter performed experiments to establish the timing of conscious volition. They both found that certain non-conscious brain events significantly preceded conscious intention. The apparent implication of their findings is that antecedent non-conscious brain events cause our actions, rather than conscious "choices". We generally believe that free choices are made consciously. If our conscious choices were not the cause of our actions, we would not be free, since being free presumably at least means that we consciously choose what we wish to do.

This evidence in itself does not pose a threat to the possibility of free-will without further interpretation, however. Some researchers who argue for the existence of free-will nonetheless take it for granted that some form of neurological determinism is true. But what makes the work we shall examine here interesting, is that the evidence we have seems to indicate that brain processes substantially precede and cause conscious mental activity. In other words, if free choice is necessarily conscious, then we could not be choosing our actions (in the traditional sense) if our brain processes preceded our mental processes; our mental processes would turn out to be merely epiphenomenal; ${ }^{2}$ they would lack a causal role.

1 The author wishes to thank Prof. Mark Leon of the University of the Witwatersrand for his innumerable valuable insights on this paper.

2 Epiphenomenal" refers to something caused, but which has no causal impact itself (Dennett, 1993:402). 


\section{Section 2 - The Experiments \\ Libet}

In a variety of articles, Libet has provided evidence that a change in the voltage of the brain, called "readiness potential" (RP) - occurs before intentions or actions do. ${ }^{3}$ $\mathrm{He}$ reported that the onset of the $\mathrm{RP}^{4}$ precedes action by about 0.8 seconds (Libet, 1985:529). Given this relatively long time, Libet was interested in establishing where the conscious intention occurred in time. We normally think that the intention is the immediate cause of the action, and thus, presumably, conscious intention should also occur 0.8 seconds before the action. But, from our own introspection, this does not appear to be the case; we are familiar with the experience of our volition seeming to occur very shortly before our action, not as long as almost one second before.

The subjects in Libet's experiments were asked to decide, arbitrarily, when to flex their wrists, while watching a moving spot on a cathode ray tube. They were asked to report the position of the dot on the tube (after flexing their wrists) - i.e., where the dot was at the time when they experienced the intention to act. Libet found that the experimental subjects consistently reported that their inclination to move occurred 0.2 seconds before they actually flexed their wrists. This is expected according to our own experience: our decisions to act do seem to occur very shortly before our physical actions. Libet found, however, that there was a significant increase in the readiness potential (RP) approximately 0.55 seconds before the act of wrist-flexing. In other words, the brain was preparing to move the wrist 0.35 seconds before the subject of the experiment had "decided" to move his or her wrist! Libet's conclusion was that this may threaten the concept of free-will, since we would expect the RP to start at the same time as the intention.

Näätänen (1985:549) reports the same results for his experiments. He tried to "fool the RP generator" in the brain by first concentrating on the task of reading, and then suddenly doing something else. Näätänen expected to see only a short RP increase before the act. However, he saw an RP of the usual duration, even though he had thought the act was very spontaneous. In other words, even apparently spontaneous actions, without any preparatory thinking, produced a lengthy RP stage - i.e., were not really spontaneous. Libet summarises the findings as follows:

Voluntary acts are preceded by ... RPs. ... With spontaneous acts involving no preplanning, the main negative RP shift begins at about $-550 \mathrm{~ms}$.... The time of conscious intention to act was obtained from the subject's recall of the spatial clock position of a revolving spot at the time of his initial awareness of wanting to move (W). W occurred at about $-200 \mathrm{~ms}$. Control experiments, in which a skin stimulus was timed (S), helped evaluate each subject's error ... RP onset preceded the uncorrected Ws by about $350 \mathrm{~ms}$ and the Ws corrected for S by about $400 \mathrm{~ms}$... It was concluded that cerebral initiation of a spontaneous voluntary act begins unconsciously. ${ }^{5}$ However, it was found that the final decision

3 The best presentation occurs in Libet (1985). See also Behavioural and Brain Sciences (1987, 1989, 1990).

4 Discovered by Deecke et al.

5 It is important to note that throughout his article and its responses, Libet and others use the term "uncon-scious" to mean "non-conscious". "Unconscious" is usually taken to refer to a mental event of a 
to act could still be consciously controlled during the $150 \mathrm{~ms}$ or so remaining after the specific conscious intention appears." [My Italics] (Libet: 529). ${ }^{6}$

If a non-conscious brain event was the true cause of an action, and the decision to act came later in time, then it is apparent that it is not our "decisions" that make us do what we do - or at least - not entirely; a non-conscious brain event also plays a necessary role. This sequence of events is most clearly depicted on a time-line, represented in Fig. 1. ${ }^{7}$

\begin{tabular}{lll}
\hline & & \\
$-0.55 \mathrm{sec}$ & $-0.20 \mathrm{sec}$ & $0.0 \mathrm{sec}$ \\
brain event (RP) & awareness of intent (W) & the act
\end{tabular}

\section{Fig. 1 - Libet's Findings - 1}

Libet's concern, therefore, was that $\mathrm{W}$, the feeling of wanting to move, might play no role in the formation of an act; he was worried that it may just be epiphenomenal, and so not even play an intermediary role between the choice and the act. Libet's evidence thus shows that there is some non-conscious brain event (RP) which precedes our awareness of wanting to move. These results, if correct, might strip us of free-will, because we assume that the will alone (with proper associated functioning and contextual circumstances) should be enough to cause us to do something (see e.g. Honderich, 1973:197). We assume that it is the will, qua mental, which determines our actions.

Libet did, however, find that subjects could "veto" a decision. That is, the subjects were told to sometimes change their minds and cancel their decisions. They often reported being able to do so, and their reports indicated that a conscious decision to not perform the act occured in the last 0.15 seconds. Libet seemed to think that this was the elbow room for free-will. Libet's evidence also indicates that our decisions are more like choices between doing something or refraining from doing that same thing; our choices are more like [ A or not-A ], rather than [ A or B ]. Choices, if Libet's evidence is correct, are more like preventative control mechanisms - "vetoes" (1985:529), rather than "triggers" (ibid.:538). But as we shall later see, this "veto" concept entails some substantial problems.

Freudian type, which could at least in principle be accessible to consciousness (e.g. through therapy). Libet's "unconscious" events are however in fact non-conscious - they are not accessible to consciousness at all. All quotations in which the word "unconscious" appears, therefore, should be read in the light of this interpretation. It is clear when reading Libet that he means "non-conscious", not Freudian-unconscious.

6 Libet actually found two types of RP: type I and type II. The type-I RP appeared before consciously pre-planned actions, and lasted up to about a second before such actions. The type-II appeared about half a second before spontaneous but nonetheless deliberate actions. This implies that, in the case of pre-planned actions, we have an even longer prior non-conscious preparatory stage (1987:785; 1985:531, and 1990:672). This paper concentrates on type-II RP events, since these were the bulk of the types of events that Libet investigated. Thus all actions, whether deliberated and slowly decided or not, have an antecedent RP.

7 Note that the diagrams are a substantial simplification of Libet's result graphs, and my diagrams should not be read to entail that the events depicted are not connected by any other events, i.e., that they are discrete. Note also that the timing of zero time (the act) was measured accurately by an electromyogram attached to the appropriate muscle. 


\section{Grey Walter}

W. Grey Walter independently performed a similar work ${ }^{8}$ before Libet ${ }^{9}$ conducted his experiment. The subjects (who were brain surgery patients) were asked to press a button to "change" a viewing-slide at any arbitrary time that they desired. The button, however, was a dummy, and the slide was actually changed by an amplification of the RP signal from their brains. The subjects consistently reported that it was as if the slide projector had a kind of bizarre precognition, because it would change the slide before they had decided to change the slide. The subjects reported feeling unnerved that they might accidentally advance the slide twice.

This again illustrates that evidently, the real cause of the act is some non-conscious brain event (possibly RP), and that it occurs in time before the subjective, first-person apparent decision event. Our "decisions", as we think of them, may be merely mental epiphenomena, caused by an antecedent neurological event, which is non-conscious, and which in itself is the actual determinant of the decision event. ${ }^{10}$

\section{Implications}

The experimental results of both Libet and Grey Walter seem to point to the conclusion that what we call "decisions" or "intentions" are actually mental states caused by non-conscious neural events - and that the conscious aspect of decision-making may be a mere side-effect or epiphenomenal feature of making decisions, without a causal role in our actions.

Contrary to our intuitions, the experiments seem to show that our conscious choice is not a sufficient cause for our actions.

"This [work] seems to show that your consciousness lags behind the brain processes that actually control your body. Many find this an unsettling and even depressing prospect, for it seems to rule out a real (as opposed to illusory) 'executive role' for 'the conscious self"' (Dennett, 1993:163).

We normally think of our choices as conscious volition that causes action directly:

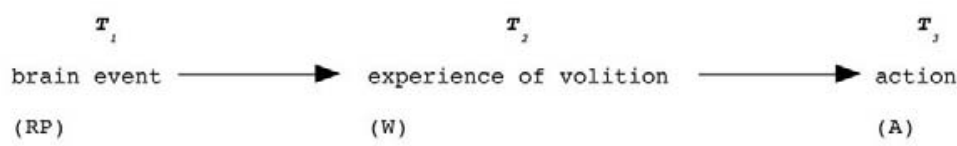

Fig. 2 - What we believe about choice

If we refer to Figure 4.1, however, we see that Libet's results indicate that this is more like what is actually the case:

8 1963. Presentation to the Osler Society, Oxford University, in Dennett, Consciousness Explained (1993:167), also in Dennett and Kinsbourne (1992:199).

9 He did not attempt to investigate "veto" possibilities.

10 Dennett raises an objection to both this and Libet's evidence as examples of bad thinking about the mental. He argues in the relevant chapter in his (1993) book that there is no "finishing line" in timing consciousness. However, I argue that the fact that the experimental subjects experience the slide advancing (in the Grey Walter experiment) as alarming, means that they were not aware of their decision having been taken, and that it was in fact occurring non-consciously, prior to their awareness. 


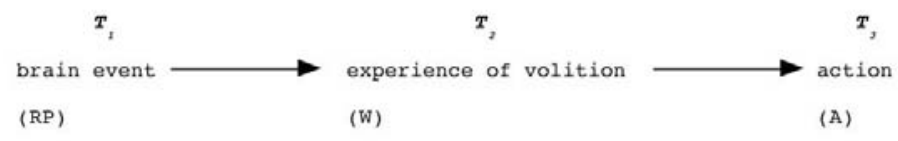

Fig. 3 - Libet's Findings - 2

But if Libet has found something to genuinely be concerned about, then the facts of the matter must look something more like this - in which the experiencing volition plays no causal role:

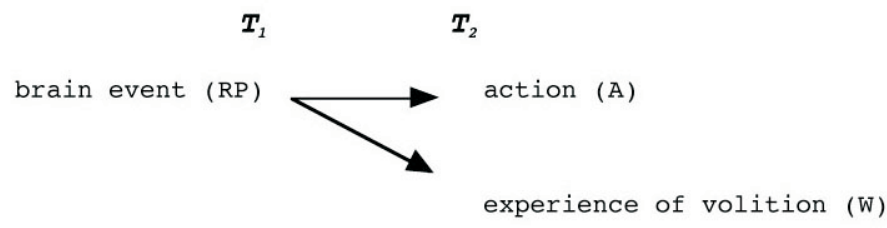

Fig. 4 - The real concern

Let me interpret this diagram to make it clear. If Libet's findings are anything to be concerned about, RP would have to cause the volition experience, and RP would have to be sufficient cause for action, with the volition experience (W) and the action (A) having no causal role in relation to each other. They would have to be independent effects of RP. This is what Fig. 4 above illustrates.

Let me give a preliminary indication as to why this process (Fig. 4 above) may be correct.

Firstly, Libet points out that no special spike in the RP graph seems to correlate with the conscious intention timing W (1985:535). In other words, on his readings, W did not seem to be represented on the graph. This could mean that it was part of the readings he was acquiring, or it somehow supervened on the electrical signal he was reading. I am suggesting that $\mathrm{W}$ is not relevant to the final action, and what Libet was graphing were the brain activities that caused the final action. Hence, the absence of any apparent spike on the graph representing $\mathrm{W}$ suggests that $\mathrm{W}$ was not involved in the causal sequence leading up to the action.

Secondly, if the conscious experience of volition - W - is to play a role, we may have reason to expect it to be at least simultaneous with the RP. But it is not; it occurs after RP every time, which suggests that it is at most an effect of the RP, not a supervenient concomitant. ${ }^{11}$ Thirdly, there is a concern that if W and RP both play a role, this may involve a case of overdetermination of the action. Consider the case of automated actions, e.g. tying one's shoelaces. In these cases, the non-conscious RP is both necessary and sufficient, hence it seems that $\mathrm{W}$, in these cases, is neither necessary nor sufficient. Hence it strikes me as dubious that in deliberated cases, W would be either necessary or sufficient. Furthermore, Libet says:

11 These are Libet's views and represent his concerns with the implications of his own results. 
It might be argued that unconscious initiation applies to the kind of spontaneous but perhaps impulsive voluntary act studied here, but not to acts involving slower conscious deliberation of choices of action. ... Even when a more loosely defined conscious preplanning has appeared a few seconds before a self-initiated act, the usual specific conscious intention to perform the act was consistently reported as having been experienced separately just prior to each act by all subjects... This leads me to propose that the performance of every conscious voluntary act is preceded by special unconscious cerebral processes..." (Libet, 1985;536). [my italics]

\section{Section 3 - Criticisms ${ }^{12}$}

Why then do we think we are consciously choosing our actions?

Assuming, however, that Libet's evidence is correct, why then would we persist in the belief that our conscious selves control our bodies? We have two possible reasons for persisting in this belief. Are we to attribute the choice of action, or our motion, to the RP, or something even prior to that? The RP occurs in a context where the person, presumably, has already done some pre-planning about what he or she wishes to do, perhaps several days or hours before. So the conscious choice may yet precede the RP. I acknowledge this is a possibility but I suggest in my conclusion (Section 5 below), that even these prior planning phases have their own non-conscious phases. To suggest otherwise would be to posit some form of dualism, or perhaps a form of supervenience theory. But this debate as to the merits of various theories of the nature of mind is beyond the scope of this paper.

The second reason why we persist in believing in our free choice, given this evidence, has something to do with the timing. Given that a neural transmission from the brain can take about $0.175 \mathrm{sec}$ (Dennett, 1993;103) to reach the muscles, ${ }^{13}$ and given that Libet says that awareness (W) is reported as occurring approximately $0.2 \mathrm{sec}$ before the act, it is unsurprising that we would think that consciousness is the cause of the action - because consciousness and motor instruction $(\mathrm{M})$ are almost simultaneous. However, for consciousness (W) to causally contribute to our actions, it should clearly precede the motor instruction (M), but it does not. Our illusion of self-control must come from this timing similarity, whereas, in fact, the two events are roughly simultaneous. To represent this graphically:

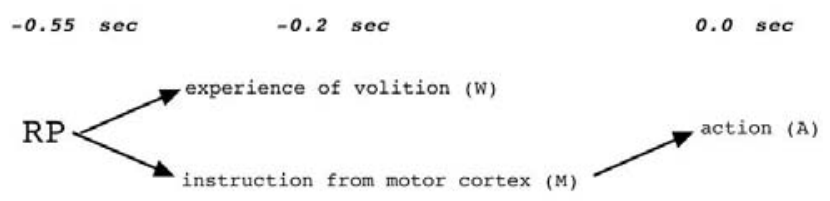

Fig. 5 - What seems to be happening

12 Grey Walter is only published in Dennett (1992 and 1993) (Dennett, personal communication, 2001); thus we shall focus our attention on Libet.

13 Starting and stopping a stopwatch. For a speech act it is worse, at $0.2 \mathrm{sec}$. 
Libet reports that subjects could accurately report the timing of the instruction to actually move (M) (1985:535). Hence, because W and M are timed very closely, we get the impression that $\mathrm{W}$ is causing the action, whereas Libet's evidence seems to indicate that only $\mathrm{M}$ is causing it, and that $\mathrm{W}$ and $\mathrm{M}$ seem to have no causal interaction.

\section{A Compatibilist's Objection}

A compatibilist in respect to the free-will debate ${ }^{14}$ will readily acknowledge the role of antecedent causation in determining our choices, and yet such a theorist would not feel that Libet's evidence necessarily poses a threat to our free-will. Consider this: on most compatibilist models, an agent is free if she can get what she wants because she wants it, and what she wants to get is in her best interest, or in accordance with her best reasons. Libet's work does not oppose such a model directly. Even if an agent's actions are antecedently determined by a neural event, the agent could still be said to get what she wants because she wants it. The question, rather, is one of the causal efficacy of those wants and desires, i.e., whether Libet's work entails that our mental processes are epiphenomenal. If the wants and desires were necessary for carrying out the action on a compatibilist model, then the agent could still have free-will. If, however, the neurological event alone was enough, and the mental events were not causally efficiacious qua mental, then they could be irrelevant to the eventuation of the action choice, and a compatibilist response will fail.

When we talk of "an agent getting what she wants", the question is whether we are talking about the causal efficacy of the RP, or the causal efficacy of the mental state qua mental, or both (assuming that "wants" are mental and efficacious qua mental). If the mental is not efficacious - and this seems to be Libet's concern - then the wants and desires would not be efficacious. Hence, we would say that the agent gets what she wants because of a non-conscious RP, which is not the same as having free choice on the compatibilist model. In other words, even if the compatibilist construal of free-will is correct, Libet's results seem to show that agents do not have free-will of the sort that compatibilists describe.

\section{Further Criticisms}

Further criticisms of Libet's work are available in the literature, so for the sake of brevity, I refer the interested reader to the responses in Behavioural and Brain Sciences (1985, 8:4). Briefly, most responses in the literature query Libet's stance on the Mind-Brain Debate - suggesting he is implicitly a dualist, or querying whether epiphenomenalism is a plausible account, and whether prior conscious decisions could not have set up the RP in advance. I believe Libet answers most of the queries about his work successfully, and that there are no substantial issues with his work apart from the one I raise in this next section.

\section{Section 4 - Libet's "Veto"}

Libet found evidence that subjects could "veto" their decisions at the last moment. They were able to change their minds. Libet felt that this indicated that we do have some room for free-will. I do not, however, believe that his results entitle him to hold this position. Let us see why.

14 A philosopher who holds that free-will is not incompatible with determinism. 
Libet's graphs of the RP in the case of an action, then the case of a veto, look something like this ${ }^{15}$
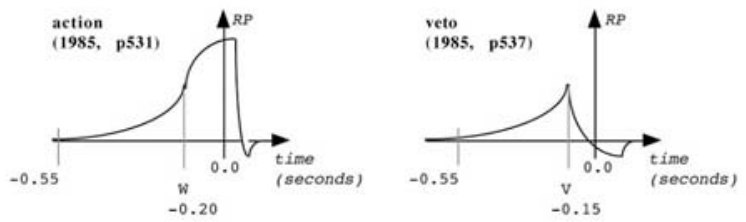

Fig. 6 - Libet's Graphs of Action and Veto

Libet says:

... the present experimental findings and analysis do not exclude the potential for 'philosophically real' individual responsibility and free-will. Although the volitional process may be initiated by unconscious cerebral activities, conscious control of the actual motor performance of voluntary acts definitely remains possible. The findings should therefore be taken not as being antagonistic to free-will but rather as affecting how free-will might operate ... The concept of conscious veto or blockade of the motor performance of certain intentions to act is in general accord with certain ... views of ethical behaviour... 'Self control' of the acting out of one's intentions is commonly advocated." (1985:538-9).

Libet also takes pains to point out (1987:783) that, although "W" is referred to as "wanting", W is not the actual choice. Rather, for Libet, choice or free-will comes into effect at the veto stage - subsequent to W (1987:784). Choice therefore can only occur in the last 150ms or so of activity (1987:785). In other words, free-will, as we know it, can at best be a matter of self-control; where we "block" a choice or inclination from following through to action.

Libet is also quite clear that, in order for free-will to operate, the "vetoes" cannot have antecedent non-conscious neurological causes. On page 538 (1985), he says:

Would the appearance of a conscious trigger or veto also require its own period of prior neuronal activity, as is postulated for the development of the conscious urge or intention to act and for a conscious sensory experience? Such a requirement would imply that conscious control of the volitional outcome, whether by veto or by an activating trigger, is itself initiated unconsciously. For control of the volitional process to be exerted as a conscious initiative, it would indeed seem necessary to postulate that conscious control functions can appear without prior initiation by unconscious cerebral processes, in a context in which conscious awareness of intention to act has already developed [Italics are Libet's, bold typeface my emphasis].

There are several problems with Libet's treatment of the veto process, which I now discuss.

15 These diagrams greatly simplify the RP measurements which actually appear as a jagged line. 


\subsection{No neural correlate at all, or a simultaneous neural correlate?}

The first anomaly one might notice is Libet's assertion that veto lacks antecedent non-conscious neural causes. He clearly says "it would indeed seem necessary to postulate that conscious control functions can appear without prior initiation by unconscious cerebral processes" (538). This is problematic, because it is as if he is saying that the veto appears out of nowhere. Libet has to take a stance on the mind-body debate (Breitmeyer, 1985:539). Unless he wishes to commit himself to dualism (Nelson, ibid.:550), he has no choice but to assume that the conscious veto is associated with a non-conscious neurological event as well. Whether it be antecedent, like RP, or a supervenient relationship with the neural correlate simultaneous with $\mathrm{V}$, there has to be a neural correlate (1985:538-9).

One might even be tempted to read Libet as saying that vetoes are not preceded by any neurological events at all. If he does indeed mean that, he could be leaning towards the view of dualism. For consider; he seems to be suggesting that $\mathrm{V}$ appears ex nihilo; lacking an brain state. But perhaps he is not suggesting this. Perhaps, in denying that vetoes have antecedent non-conscious neural events, Libet means that vetoes are preceded by neurological events, but that they are conscious. Or perhaps, in saying that $\mathrm{V}$ appears without an antecedent RP, he could be suggesting something like supervenience theory; viz., that simultaneous with $\mathrm{V}$ is a neurological event which needn't be an RP, which nonetheless is the neural correlate of V, and which is causally efficacious at halting the choice. Thus, it is unfair, prima facie, to accuse Libet of dualism. Perhaps the charge of dualism would stick if Libet were suggesting that $\mathrm{V}$ had no neural correlate. His work is not perfectly clear on this matter, however. Perhaps V can be causally efficacious because it supervenes on some simultaneous neurological state, whereas W is not causally efficacious, because it succeeds the causally efficacious RP. While is a plausible interpretation of what he means, it also leads us to the next matter of concern.

\subsection{Imbalance and inconsistency}

Libet, as we have seen, seems to want to allow the vetoes to exist without prior RPs, so that some kind of mental causal efficacy could prevail (Danto, 1985:541; MacKay, ibid.:546; Nelson, ibid.:550; Libet, ibid.:538). Libet seems to suggest that the veto could do its work, and that the veto is efficacious qua mental. But at the same time, Libet is worried that $\mathrm{W}$ requires a prior RP to be causally efficacious, and that $\mathrm{W}$ is not efficacious qua mental. There is an imbalance here: why is Libet worried that $\mathrm{W}, \mathrm{a}$ mental event, may lack causal efficacy vis a vis the eventual action (A), but V, which is also a mental event, apparently has causal efficacy? This is inconsistent.

Since Libet is worried that the RP makes W superfluous, it seems that he cannot consistently argue that veto (V) is causally efficacious (or if it is, that W is not), without explaining why there is a relevant difference, such as the presence or absence of RP. In other words, Libet is worried that RP makes W inefficacious, and postulates that the absence of RP for $\mathrm{V}$ makes $\mathrm{V}$ efficacious.

If $\mathrm{V}$ is causally efficacious, $\mathrm{W}$ must be as well, because they are both decisions and mental events. On could think of it as follows: In the case where there is no veto, there is an RP and a W, and the action occurs. This means that either RP, W or both are the cause of the action. If however, there is a veto, V, then neither RP nor W seem efficacious; only V seems to be. Let us assume that RP is the cause of action in the non-ve- 
toed case. Why then, would $\mathrm{V}$ be causally efficacious if $\mathrm{W}$ was not? $\mathrm{V}$ is a mental event, just like W. So if V is efficacious, W should be as well. Now if W is causally efficacious and determined by RP, then we would expect that, in order for $\mathrm{V}$ to be causally efficacious, it would have to be inside the causal chain, and must itself be causally determined by something else in the brain; presumably another non-conscious brain state similar to RP. Yet Libet denies this.

There are a number of possible interpretations we could employ in trying to make sense of this aspect of Libet's work.

Interpretation A) $\mathrm{W}$ and $\mathrm{V}$ are causally necessary for action, and we have free-will because $\mathrm{W}$ and $\mathrm{V}$ are causally efficacious. V and $\mathrm{W}$ both are supervienient states that have RPs or other neural correlates, and [ RP and W ] or [ RP and V ] are jointly sufficient and necessary for an action choice.

The problem with this interpretation is that it is clear that Libet feels his evidence excludes the causal efficacy of $\mathrm{W}$, but that $\mathrm{V}$ is nonetheless efficacious. If we want to make sense of his work, then either $\mathrm{V}$ and $\mathrm{W}$ are both causally efficacious, or neither is. If he has in fact found something interesting (that $\mathrm{W}$ is not efficacious), then it would be inconsistent to say $\mathrm{V}$ is efficacious. The only way that Interpretation A can be workable, is if we found evidence that RP and W are both necessary for action. But Libet's evidence appears to show that only RP is necessary. Recall the earlier example of the automated actions cited in Libet and Näätänen - RP is present no matter how spontaneous the action is, and it always precedes $\mathrm{W}$ subsantially.

One could also consider the following:

Interpretation B) W is causally efficacious and part of the causal chain, but it is not free, because it is caused by RP, whereas V is not caused by RP, so it is able to act without the determination of RP. If this were the case, then W would be causally efficacious but unfree, whereas $\mathrm{V}$ would be causally efficacious and free.

There are two questions here. Firstly, there is the question of the implicit incompatibilism. This interpretation suggests that what makes an action free or not is the matter of whether it has a prior (RP) cause. A compatibilist would regard W as free even with a prior cause, because $\mathrm{W}$ may simply represent the want of the agent, which is ultimately satisfied. Without launching into a defense of incompatibilism (for the sake of brevity), I can answer this briefly as follows: If $\mathrm{W}$ is caused antecedently by $\mathrm{RP}, \mathrm{W}$ can only be free if $\mathrm{W}$ is in fact causally efficacious. Since $\mathrm{W}$ is not causally efficacious, W can therefore never represent a Will that is free, even on a compatibilist interpretation. ${ }^{16}$

Secondly, if the RP or our antecedent choice is sufficient cause for action, why do we need the additional veto event to explain it, or make it free? (Mortensen,1985:548).

Finally, if Interpretation B were to be even remotely viable, it would leave us with the usual question of imbalance, namely: why does V lack an RP? Libet is clear that he did not detect an RP, certainly his empirical evidence seems to indicate that V has no RP, but W does, but this just does not make sense. Perhaps it was lost in the signal noise on the graph, or there was some other non-conscious antecedent neurological cause. Of course, V could have been determined or caused by some other non-RP neu-

16 I will provide substantial proof that $\mathrm{W}$ is not causally efficacious and that $\mathrm{W}$ and $\mathrm{V}$ are epiphenomenal in the sections that follow. It has to do with the timing 
rological event. But whether $\mathrm{V}$ is determined by an RP or not, $\mathrm{V}$ has to be determined by some neurological event (assuming that dualism is false). But Libet's belief is very clearly that V is free-will, because V lacks an RP. It seems as if Libet may be accepting incompatibilist intuitions here: that a neurological cause of $\mathrm{V}$ would render $\mathrm{V}$ unfree. My concern is that $\mathrm{V}$ and $\mathrm{W}$ are both the same kind of thing: $\mathrm{W}$ is the wanting-to do something, and $\mathrm{V}$ is the not-wanting-to do something. They are both mental, both intentional, and both about an action. Therefore, surely, they must have very similar causal antecedents? This is the inconsistency that I, together with other commentators on Libet, are concerned about. Certainly, if V is causally efficacious, it exhibits that the mental is causally efficacious. But then, in retrospect, this would suggest that W would have to be causally efficacious. Yet it is clear that Libet thinks that $\mathrm{W}$ is not causally efficacious. This is why Libet is inconsistent, but Interpretation B does seem to represent his position accurately.

Interpretation $\mathrm{C}$ ) Neither $\mathrm{V}$ nor $\mathrm{W}$ are causally efficacious; rather, they are epiphenomenal states with RP or other antecedent neural correlates, and these neural correlates alone are sufficient and necessary for action.

This is the interpretation that I favour. I will provide the evidence for this in my later discussion of the details of timing for the various events.

\subsection{That free-will is more than just changing your mind}

It is quite clear from Libet $(1985: 539)$ that he believes the capacity to perform a veto constitutes free-will (1987:784). What are we to think then? Suppose W is not free because it is determined antecedently by a non-conscious RP. Then any action caused by $\mathrm{W}, \mathrm{RP}$ or both would also not be free. Thus, except in those circumstances where we change our minds, our actions are always unfree. But if $\mathrm{V}$ intervenes and cancels $\mathrm{W}$, this means that we are only free if $\mathrm{V}$ intervenes. This strikes me as a poor shadow of free-will, because we tend to think we are free when we want to do something and do it; it is not the case that we are only free when we happen to change our minds. To put it another way, suppose when we only have W and RP, the action is not free because only RP is the cause of the action. This seems to be what Libet believes. Now suppose that, under a vetoed case, we are free because V has no antecedent RP. This also seems to be what Libet believes. But this means that, if Libet is saying that $\mathrm{V}$ is free-will, then all cases where we act but do not change our minds mean that we are not free, since free-will requires $\mathrm{V}$ (changing your mind). This strikes me as odd, to say the least. A compatibilist might object to the possibility of doing otherwise at this point (the alternative possibilities argument). I will address this concern inSsection 4.5.

A further consideration regarding the freedom of choice to do things, and not just to cancel them, occurs in Doty:

"If the preparatory movement is wholly outside conscious control, how could a conscious process then 'know' what will ensue if it fails to veto the brain's proposal? In this scheme, consciousness is relegated to an intuitive process of guessing what it may be that 'the brain' is up to..." $(1985,: 542)$.

How, in other words, could we possibly know what we are going to choose, in order to veto it, if $\mathrm{W}$ is not under our control? How could it be that we could not be free when generating $\mathrm{W}$, and yet when generating a change of mind $-\mathrm{V}-$ we are free? This is inconsistent. 


\subsection{Why W and V may both not be causally efficacious - Evidence for epiphenomenalism}

Apart from the inconsistency in Libet, the most substantial reason for rejecting the causal efficacy of V is this: Libet's evidence shows that $\mathrm{W}$ occurs at the same time as M (the cortical initiation of the action). Thus, we have no good reason to suppose that $\mathrm{W}$ contributes to the eventuation of M. Rather, it appears that W, like M, is merely an effect of RP. Recall our earlier diagram (Fig. 5). Since M and W occur simultaneously, they are both effects of RP. I venture that W is the epiphenomenal experience of RP.

Analogously, and this is the crux of the matter: since V occurs shortly after M, we have no reason at all to suppose that it is responsible for influencing M; rather, there must be some antecedent neurological event that halted $\mathrm{M}$ in the veto case. Remember, neurological transmission time from the motor cortex is at best $175-200 \mathrm{msec}$, which gives $\mathrm{V}$ or $\mathrm{W}$ no time to influence $\mathrm{M}$. Since $\mathrm{V}$ occurs at $150 \mathrm{msec}$ before the action, and since $\mathrm{M}$ occurs at $175-200 \mathrm{msec}$ before the action, V cannot stop $\mathrm{M}$ from travelling down the arm to the hand, because the signal has already been sent. This means that $\mathrm{V}$ cannot be causally efficacious, because it occurs too late. Libet reports that "neuronal adequacy" or awareness of neurological events takes around $200 \mathrm{msec}$ to be realised after the neurological event (cf. Libet, 1982); therefore V and W, qua "neuronally adequate", could not influence M in time, because they take $200 \mathrm{msec}$ to reach that state. In other words, while $\mathrm{W}$ and $\mathrm{V}$ are building up to achieve neuronal adequacy over the $200 \mathrm{msec}$ period, the same RP that caused them also initiated the M signal; when we experience $\mathrm{V}$ or $\mathrm{W}$, we experience the epiphenomenal effect of a neurological event that occurred $200 \mathrm{msec}$ earlier.

What, then, causes the veto event? If it takes the consciousness about $200 \mathrm{msec}$ to become apprised of a neural event, and if RP is the neural correlate of W, occurring about 300 msec before $\mathrm{W}$, we would expect there to be an antecedent brain state before V. Since V occurs at about $-150 \mathrm{msec}$, we would expect its neural correlate to occur at about $-350 \mathrm{msec}$ to $-450 \mathrm{msec}$. That neural event would be far enough back in time to cause $\mathrm{M}$ to halt. My suspicion is that, were Libet to redo his experiments and measure for veto brain events, he would find something more like Figure 4.7 below. I am hypothesising, for the sake of future experimental testing, that antecedent to the veto decision, $\mathrm{V}$, there will be another brain event, let us call it $\mathrm{RP}(\mathrm{v})$, which is the neurological antecedent of V, just as RP (here called RP(w)) - which Libet detected is the neurological correlate of W. ${ }^{17}$

It is possible that, under experimentation, Libet might not find an RP per se for veto, because RPs are typically associated with physical movements (Wood: 558, Libet: 562). However, Libet should at least see some neural activity indicating prior brain events that lead up to the later consciously-experienced veto.

17 In this diagram, $\mathrm{RP}(\mathrm{v})$ is the neural event preceding and sufficiently causing the veto, and $\mathrm{RP}(\mathrm{w})$ is the neural event preceding and causing the act $\mathrm{M}$ (unless a veto occurs). I am not committing to the view that there is an RP as such prior to V (veto), just that there is some neural correlate of V. It is called $\mathrm{RP}(\mathrm{v})$ for ease of analogy. 


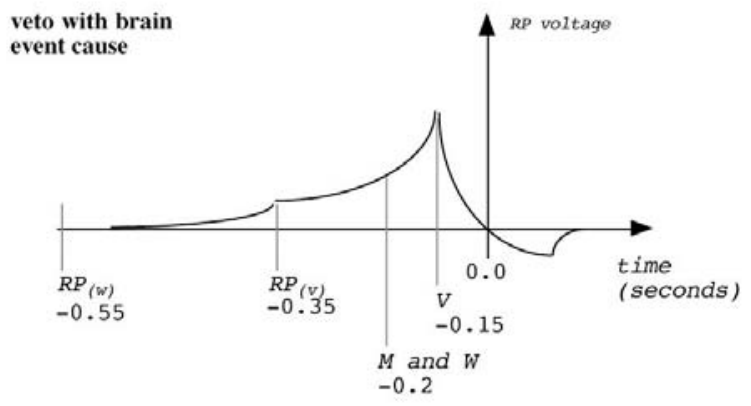

Fig. 7 - A possible solution

\subsection{Compatibilist objections to my interpretation}

One might be concerned about other philosophical and less technical issues in Libet's findings. We have already seen the familiar compatibilist objection - that as long as we can get what we want, and we get it because we want it, we are free. This was rejected on the grounds of questions around causal efficacy. The compatibilist requires that we get what we want (true, under Libet's paradigm), because we want it (false, under Libet's paradigm; we get it because the RP caused some bodily motion). But there is another concern.

The mere possibility that we can change our minds, it could be argued, might give us some measure of free-will; that in some possible world, we do in fact have free-will. This is what Libet seems to believe sufficient for free-will. But it is apparent that this is not an adequate kind of free-will, for the two reasons already discussed. Firstly, we believe that we are free when we choose to do something, not only in those cases where we choose to refrain from doing something. Secondly, we believe that we have free-will just in case we get what we want because we want it. Since it is the wants themselves that are not efficacious, viz., neither $\mathrm{W}$ nor $\mathrm{V}$ are efficacious, it is apparent that we do not get what we want because we want it; we get what we want because of RP. Perhaps if there were proof that epiphenomenalism were not the case, then $\mathrm{W}$ and/or V could be causally efficacious. But only in such a case would we in fact have free-will in any true sense.

Perhaps another way to express this concern is with the conditional interpretation of alternative possibilities: If the agent chooses otherwise, then the agent would do otherwise. One can argue that we are free just in case if we decide or choose otherwise, we would do otherwise. And since veto exhibits that we could do otherwise if we so decide, we could conclude that, even in non-vetoed cases, we could do otherwise, and hence we are free.

There are some residual concerns, however. Firstly, the veto might be epiphenomenal, and hence even if it exhibits a change of mind, it does not exhibit a change of mind where the change of mind is causally efficacious qua mental. This means the change of mind is not freely willed. Secondly, the mere logical possibility of having free-will is not enough to ground moral responsibility. 
If determinism is true, then clearly, in some sense, there are no alternative possibilities." [sic]. "... Relative to the laws of nature and antecedent conditions, it is not possible that one does anything but what one does." (Watson 1987:154). ${ }^{18}$

Neither Watson (himself a compatibilist), nor I are arguing that there is no meaningful way in which we can talk about alternative possibilities. Rather, Watson is expressing the same worrying intuition I have about the relevance of the causal past. The problem he suggests is that ultimately, what we do is a result of what we desire, and it is not obvious that what we desire is up to us. I believe that this intuition lies at the heart of the incompatibilist's worries about free-will. ${ }^{19}$ Glover puts it this way: "I can do what I want, but can I want what I want?" (Glover:458). The conditional analysis of alternative possibilities asserts that, if our needs had been different, what we wanted would have been different. But Watson's point is just that the laws of nature, and the antecedent causal past, ensure that we only choose one path every time. "An action is free in the sense required for moral responsibility only if it is not produced by a determinisitic process that traces back to causal factors beyond the agent's control." (Pereboom, 3).

The kind of free-will worth wanting is the kind that will secure our moral responsibility. Libet's evidence seems to show, however, that at best we have a watered-down kind of free-will, in which we have only negative responsibility; viz., moral responsibility in those cases where we vetoed a decision. It would not give us positive responsibility; viz., responsibility for the actions we carry out.

\section{Section 5 - Summary and Conclusion}

Libet appears to be seduced by the idea of free-will and control over his actions, and despite his own evidence that actions are non-consciously initiated, Libet wishes to privilege "veto" acts as not having antecedent non-conscious physical causes in order to rescue free-will. Libet could argue that vetoes are associated with conscious neurological events, and hence represent free choice, but then he would still be guilty of inconsistency. For Libet is concerned about the possibility that $\mathrm{W}$ is not causally efficacious: indeed, his fear was that the preceding RP indicated that $\mathrm{W}$ was just the experiencing of the volition to move. Libet is very careful about this. He never calls "W" the "will" - the decision-making entity. W is always characterised as the awareness of wanting to do something. Libet is quite clear that $\mathrm{W}$ (the awareness of wanting to do something) is not the will per se, which is manifest in the later "veto", occurring at -0.15 seconds (Libet, 1987:784). This is a distinction that Libet makes because he wishes to preserve the power of the will to decide, qua mental. In the case of $\mathrm{V}$, Libet is clear in his view that it is causally efficacious, and that it is a manifestation of free-will, traditionally construed. Remembering now that Libet thinks that free-will is veto, as I have already emphasised, we are left with the conclusion that, if $\mathrm{W}$ is not the will proper, then in a non-vetoed case, the will may be reduced to the role of passively waiting for a reason to intervene in actions somehow spontaneously generated in the non-conscious part of our minds (Doty, 1985:542). This sounds odd. Surely we can

18 This is not meant to disprove compatibilist freedom; Watson is a compatibilist. But it is a direct quotation.

19 See also Double (191) and Chisholm (50-51) for a related argument. 
freely and voluntarily initiate actions even if our choice will not involve a veto (changing our minds)?

I have argued, however, that $\mathrm{V}$ is not the decision to veto, but rather just the subject's awareness of a decision to veto. Since veto is also a mental event, and since it must be associated with a neural event, then it makes sense to assume that veto is preceded by its own neurological event that could be non-conscious and causally necessitates cacelling the event $\mathrm{M}$. But if we are correct in arguing that $\mathrm{W}$ and $\mathrm{V}$ are epiphenomenal, we may wonder why we still have or experience them. I cannot answer this with certainty; one is tempted to think that these states must have a purpose, but I cannot think what it may be, because epiphenomenal means that they have no effect. But this concerns the mind-body debate, which is beyond the scope of this paper.

The only objection to my interpretation of Libet's results that seems to have any promise, is that the one concerning the RP that forms in the context of already-chosen policies of behaviour, where the agent has already decided what he or she is going to do, and the RP is just an event occurring at the time of the act itself; it does not represent reasoning or choosing per se (McCrone and Baggot, 2000). This argument is hard to disprove, but one might speculate, in response to this criticism, that the reasoning itself, and any other mental state, would have a similar relationship of epiphenomenalism to its neural substrate. In other words, it is not just choosing to do something or choosing not to do something that has prior non-conscious neural phases; all thinking may have such phases (compare this speculation to Libet's claim in 1985:536). I recognise, however, that the burden of proof is mine.

We know that we can control ourselves in some sense, and veto our decisions. But I believe that what we decide and what we veto (if Libet's interpretation stands) is a non-conscious result of our non-conscious self-structures (see e.g. Dennett, 1993:199 et seq.). Hence, I believe that Libet's results are strong evidence against free-will.

\section{References}

Aronson, J., Dietrich, E., Way, E. 1992. "Throwing the conscious baby out with the Cartesian bath water". Behavioural and Brain Sciences, 15:2

Baars, B. 2000. "Libet replications and implications", eScribe: PSYCHE-B: Internet. http://listserv.uh.edu/cgi-bin/wa?A2 $=$ ind $0008 \& \mathrm{~L}=$ psyche-b\&P=14102 http://listserv.uh.edu/cgi-bin/wa?A2=ind0008\&L=psyche-b\&P=14217 http://listserv.uh.edu/cgi-bin/wa?A2=ind0008\&L=psyche- $\mathrm{b} \& \mathrm{D}=0 \& \mathrm{~T}=0 \& \mathrm{P}=14646 \& \mathrm{~F}=\mathrm{P}$

Baars, B.J., Fehling, M. 1992. "Consciousness is associated with central as well as distributed processes". Behavioural and Brain Sciences, 15:2

Baggot, M. (2000). "Libet replications and implications", eScribe: PSYCHE-B: Internet. http://istserv.uh.edu/cgi-bin/wa?A2=ind0008\&L=psyche-b\&P=14102 http://listserv.uh.edu/cgi-bin/wa?A2=ind0008\&L=psyche-b\&P=14217 http://listserv.uh.edu/cgi-bin/wa?A2=ind0008\&L=psyche- $\mathrm{b} \& \mathrm{D}=0 \& \mathrm{~T}=0 \& \mathrm{P}=14646 \& \mathrm{~F}=\mathrm{P}$

Breitmeyer, B.G. 1985. "Problems with the psychophysics of intention". Behavioural and Brain Sciences, 8:4 
Block, N. 1980. Readings in Philosophy of Psychology. Vol. 1. Cambridge, Mass.: Harvard.

Block, N. 1992. "Begging the question against phenomenal consciousness". Behavioural and Brain Sciences, 15:2

Danto, A.C. 1985. "Consciousness and motor control". Behavioural and Brain Sciences, $8: 4$

Dennett, D.C. 1993. Consciousness Explained. London: Penguin.

Dennett, D.C., and Kinsbourne, M. 1992. "Consciousness and the observer: The where and when of consciousness in the brain". Behavioural and Brain Sciences, 15:2.

Dennett, D.C. and Kinsbourne, M. 1992. "Escape from the Cartesian Theater". Behavioural and Brain Sciences, 15:2

Doty, R.W. 1985. "The time course of conscious processing: Vetoes by the uninformed?" Behavioural and Brain Sciences, 8:4

Eccles, J.C. 1985. "Mental Summation: The timing of voluntary intentions by cortical activity". Behavioural and Brain Sciences, 8:4

Giancoli, D.C. 1991. Physics: Principles with Applications. USA: Prentice-Hall.

Honderich, T. (ed) 1973. Essays on Freedom of Action. London: Routledge.

Honderich, T. 1993. How Free Are You? Oxford: Oxford

Honderich, T. 1984. "Is The Mind Ahead Of The Brain? - Benjamin Libet's Evidence Examined" Internet: http://www.ucl.ac.uk/ uctytho/libet1.htm. Originally published as "The Time of a Conscious Sensory Experience and Mind-Brain Theories", Journal of Theoretical Biology (1984) 110

Honderich, T. 1986. "Is The Mind Ahead Of The Brain? - Rejoinder To Benjamin Libet". Internet: http://www.ucl.ac.uk/ uctytho/libet2.htm. Originally published as "Mind, Brain and Time: Rejoinder to Libet", Journal of Theoretical Biology (1986) 118

Hoffman, R.E., and Kravitz, R.E. 1987. "Feedforward action regulation and the experience of will". Behavioural and Brain Sciences, 10:4

Jacquette, D. 1994. Philosophy of Mind. Prentice-Hall: New Jersey

Jeannerod, M. 1992. "The where in the brain determines the when in the mind". Behavioural and Brain Sciences, 15:2

Jung, R. 1985. "Voluntary intention and conscious selection in complex learned action". Behavioural and Brain Sciences, 8:4

Latto, R. 1985. "Consciousness as an experimental variable: Problems of definition, practice, and interpretation". Behavioural and Brain Sciences, 8:4

Libet, B. 1982. "Brain stimulation in the study of neuronal functions for conscious sensory experiences". Human Neurobiology , 1

Libet, B. 1985. "Unconscious cerebral initiative and the role of conscious will in voluntary action". Behavioural and Brain Sciences, 8:4

Libet, B. 1985. "Theory and evidence relating cerebral processes to conscious will". Behavioural and Brain Sciences, 8:4 
Libet, B. 1987. "Are the mental experiences of will and self-control significant for the performance of a voluntary act?" Behavioural and Brain Sciences, 10

Libet, B. 1989. "The timing of a subjective experience". Behavioural and Brain Sciences, 12

Libet, B. 1990. "Time delays in conscious processes". Behavioural and Brain Sciences, 13

Libet, B. 1992. "Models of conscious timing and the experimental evidence". Behavioural and Brain Sciences, 15:2

Libet, B. 2001. "Consciousness, Free Action, and the Brain. Commentary on John Searle's Article". Journal of Consciousness Studies, 8:8.

Lycan, W.G. 1992. "UnCartesian materialism and Lockean introspection". Behavioural and Brain Sciences, 15:2

MacKay, D.M. 1985. "Do we 'control' our brains?" Behavioural and Brain Sciences, 8:4

McCrone, J. 2000. "Libet replications and implications", eScribe: PSYCHE-B: Internet.

http://istserv.uh.edu/cgi-bin/wa?A2=ind0008\&L=psyche-b\&P=14102

http://listserv.uh.edu/cgi-bin/wa?A2=ind0008\&L=psyche-b\&P=14217

http://listserv.uh.edu/cgi-bin/wa?A2=ind0008\&L=psy-

che- $\mathrm{b} \& \mathrm{D}=0 \& \mathrm{~T}=0 \& \mathrm{P}=14646 \& \mathrm{~F}=\mathrm{P}$

McDermott, D. 1992. "Little "me"'. Behavioural and Brain Sciences, 15:2

Merikle, P.M., and Cheesman, J. 1985. "Conscious and unconscious processes: Same or different?" Behavioural and Brain Sciences, 8:4

Mortensen, C. 1985. "Conscious Decisions". Behavioural and Brain Sciences, 8:4

Näätänen, R. 1985. "Brain physiology and the unconscious initiation of movements". Behavioural and Brain Sciences, 8:4

Nelson, R.J. 1985. "Libet's Dualism". Behavioural and Brain Sciences, 8:4

Rollman, G.B. 1985. "Sensory events with variable central latencies provide inaccurate clocks". Behavioural and Brain Sciences, 8:4

Roskies, A.L., Wood, C.C. 1992. "Cinema 1-2-Many of the Mind". Behavioural and Brain Sciences, 15:2

Searle, J.R. 1999. "Consciousness". Internet. http://socrates.berkeley.edu/ jsearle/html/ articles/consciousness.html.

Searle, J.R. 2001a. "Free-will as a Problem in Neurobiology". Philosophy, 76. 2001.

Searle, J.R. 2001b. "Further Reply to Libet". Journal of Consciousness Studies, 8:8.

Stamm, J.S. 1985. "The uncertainty principle in psychology". Behavioural and Brain Sciences, 8:4

Teghtsoonian, R. 1992. "In defense of the pineal gland". Behavioural and Brain Sciences, $15: 2$

Vanderwolf, C.H. 1985. "Nineteenth-century psychology and twentieth-century electro physiology do not mix". Behavioural and Brain Sciences, 8:4 
Van Gulick, R. 1992. "Time for more alternatives". Behavioural and Brain Sciences, $15: 2$

Wasserman, G.S. 1985. "Neural/mental chronometry and chronoethology". Behavioural and Brain Sciences, 8:4

Wood, C.C. 1985. "Pardon, your dualism is showing". Behavioural and Brain Sciences, 8:4 